\title{
NOTE ON THE ELECTROLYTIC DETERMINATION OF COPPER IN SOLUTIONS CONTAINING NITRIC ACID.
}

\author{
By ELIZABETH GILCHRIST, B.Sc., AND ALEXANDER CHARLES \\ CUMMING, D.Sc.
}

(A Paper read before the Faraday Society, Wednesday, May 7, 1913.)

It is a matter of common experience that in the electrolytic determination of copper in solutions containing nitric acid it is impossible to deposit the last two or three milligrams under ordinary conditions. J. H. Stansbie * has shown that this is due to the presence of nitrous acid and that with a stationary electrode the accumulation of nitrous acid in the neighbourhood of the cathode causes dissolution of copper. "At first the current deposits the metal much faster than it is redissolved, but finally, when only traces of metal are present in the solution, dynamic equilibrium is attained, and no further permanent deposition of the metal can take place."

We might add to this statement that, with accumulation of nitrous acid in the solution, the rate of dissolution after some time often exceeds the rate of deposition.

Stansbie showed that with a rotating cathode satisfactory precipitation is obtained from solutions containing up to 3 grammes nitric acid per roo c.e. of solution and that addition of sulphuric acid was advantageous.

It appeared likely from Stansbie's results that, if the nitrous acid was destroyed by means of urea, satisfactory results would be obtainable with stationary electrodes. As a preliminary test, a solution was electrolyzed which contained 0.508 gramme of copper and 10 c.c., of concentrated nitric acid, diluted to 100 c.c. The potential between the electrodes was 2.8 volts and the current was passed for two hours. It was found that 0.120 gramme of copper was undeposited.

To a second solution 5 grammes of urea were added, the quantities and conditions being in all other respects identical with those in the first experiment; in this case only $0^{\circ} 009$ gramme of copper remained undeposited after the two hours' electrolysis.

The addition of urea evidently produced a marked improvement, but from these experiments alone the results could not be definitely ascribed to removal of the nitrous acid. In these experiments the voltage was kept constant but the current was not noted. In later experiments it was found that addition of urea raised the voltage between the electrodes (i.e., lowered the conductivity of the solution) and caused a fall in the current. In all experiments deposition was much faster in presence of urea.

The following experiments confirm Stansbie's results as to the remarkable effect of nitrous acid in promoting the solution of copper by nitric acid and prove that the urea acts by removal of the nitrous acid. Thin sheets of

\footnotetext{
* Trans. Faraday Soc., November, I9I2.
} 


\section{THE ELECTROLYTIC DETERMINATION OF COPPER I87}

electrolytic copper of equal size were placed in the various solutions for three hours and the loss in weight determined. In each case the quantities given are for 100 c.c., of solution ; Io c.c. of ordinary concentrated nitric acid (sp. gr. $\mathrm{r}^{4}{ }^{2}$ ) was added in each case and the solution diluted to roo c.c. ; the amount of nitrous acid given is the amount present per roo c.c. before addition of the urea.

\begin{tabular}{|c|c|c|c|}
\hline $\begin{array}{l}\text { No. of Experi- } \\
\text { ment. }\end{array}$ & $\begin{array}{l}\text { Nitrous Acis. } \\
\text { Milligrammes. }\end{array}$ & $\begin{array}{l}\text { Urea added. } \\
\text { Grammes. }\end{array}$ & $\begin{array}{l}\text { Weight of Copper } \\
\text { dissolved. } \\
\text { Milligrammes. }\end{array}$ \\
\hline I & 0.06 & - & 2.5 \\
\hline 2 & 0.06 & 2 & 0.8 \\
\hline 3 & $1 \cdot 5$ & 二 & 25 \\
\hline 4 & $0^{\circ} \mathrm{I}$ & - & 4.5 \\
\hline 5 & 3 & - & 140 \\
\hline 6 & 3 & $\mathrm{I}$ & 0.8 \\
\hline 7 & $3 \mathrm{I}$ & - & 240 \\
\hline 8 & $3 \mathrm{I}$ & 2 & I. \\
\hline
\end{tabular}

Experiments 7 and 8 illustrate in a marked manner the effect of urea. Experiments 2, 6 and 8 show that there is little danger of copper dissolving if urea is present. In the electrolysis experiments the presence of urea if therefore very advantageous in minimizing the risk of re-solution at the end of the experiment. If a little urea is added when deposition is complete, the current can be stopped and the vessel washed out without any resolution of copper, provided that no unnecessary time is spent on the process. The consequent large dilution which results from the ordinary siphoning method of washing is thereby avoided.

A number of experiments were made to find the best conditions for complete deposition with stationary electrodes. The electrolyses were performed in a platinum basin with a perforated platinum disc as anode. If the current used exceeded 3 amperes the deposit was usually spotted. With a potential difference between the electrodes of 2.5 to 3 volts and a current not above 3 amperes, beautiful coherent deposits were obtained. If the current was continued for any considerable time after deposition was complete the deposit usually became spotted. The following results show that complete deposition can be obtained even when the solution contains ro c.c. of concentrated nitric acid per Ioo c.c. of solution.

$$
C u \text { present }=0.5080 \text { gramme. }
$$

I. Ioo c.c. of solution containing Io c.c. nitric acid and 5 grammes urea. Potential difference about 2.8 volts. Current passed for three hours. $\mathrm{Cu}$ found $=0.5090$ gramme. Error + I mg.

2. Ioo c.c. of solution containing ro c.c. nitric acid. Current passed for two hours without urea; then added 2 grammes urea and passed current again for one hour. Potential difference from 2.5 to 2.8 volts. $\mathrm{Cu}$ found $=0.5080$ gramme. Error less than I mg.

\section{Chemistry Department,} UNIVERSITY OF EDINBURGH. 